\title{
Koni Penetrasyon Testi (CPT) İle USCS Zemin Sınıfının Belirlenmesi ve Değerlendirilmesi
}

\section{Determination and Evaluation of USCS Soil Class by Cone Penetration Test (CPT)}

\author{
İbrahim Çobanoğlu $1^{*} \oplus$, Sefer Beran Çelik 2 (『) \\ 1,2 Pamukkale Üniversitesi Mühendislik Fakültesi Jeoloji Mühendisliği Bölümü, Denizli, TÜRKIYE \\ Sorumlu Yazar / Corresponding Author*: icobanoglu@pau.edu.tr
}

\author{
Geliș Tarihi / Received: 06.04.2020 Arastırma Makalesi/Research Article \\ Kabul Tarihi / Accepted: 31.08.2020 DOI:10.21205/deufmd.2021236704 \\ Atıf șekli/How to cite: ÇOBANOĞLU, İ., ÇELIK, S.B. (2021). Koni Penetrasyon Testi (CPT) İle USCS Zemin Sinıfinın Belirlenmesi ve \\ Değerlendirilmesi. DEUFMD, 23(67), 43-53.
}

\section{Öz}

Jeoteknik çalışmaların bütününde zeminin sınıflandırılması, hem doğru temel tasarımı için ve hem de zeminin davranış biçimini öngörmek için önem taşımaktadır. Uygulamalarda zeminlerin sınıfı arazide yapılan sondaj veya araștırma çukuru çalışmaları sırasında alınan örnekler üzerinde gerçekleştirilen deneylerle belirlenebilmektedir. Bunun yanında Koni Penetrasyon Testi (CPT) ile zemin sınıfının tahmin edilmesi yaklaşımları kullanılmaktadır. Bu çalışma CPT ile doğrudan belirlenemeyen ancak tahminsel yaklaşımlarla belirlenmeye çalışılan birleştirilmiş zemin sınıfı (USCS) gruplarının gerçekte ve yerinden alınan numuneler üzerinde yapılan deney verileri ile deneştirilmesi amacıyla gerçekleştirilmiştir. Bu amaçla alüvyal bir sahada yapılmış olan 15 adet araştırma sondajı ve 15 adet CPT deney verisi kullanılmıştır. Araştırma sondajları ile elde edilmiş numuneler üzerinde gerçekleştirilen deneysel çalışmalar ile ortaya konulan USCS zemin sınıfları CPT ile elde edilen deney verileri ile belirlenen zemin sinıflarıyla karşılaştırılarak elde edilen bulgular bir arada değerlendirilmiștir. Elde edilen veriler, deneysel olarak belirlenmiş zemin sınıflarının CPT uç direnç değerleri kullanılarak belirlenmiş zemin sınıflarından büyük ölçüde farklılıklar sunduğunu ortaya koymuştur. Özellikle zeminin plastiklik durumunu belirlemede yetersiz kalan CPT yöntemi SM grubu zeminlerin sadece "Kum - Kil" şeklinde tanımlanmasına neden olmuştur. Benzer durum SC grubu için değerlendirildiğinde CPT verilerinin zemini "Kil" olarak tanımladığı gözlenmiştir. Sonuç olarak, yerinde yapılan örneklemelerle deneysel olarak belirlenmeyen zemin sinıflarının, CPT verileriyle dolaylı olarak değerlendirilmesi durumunda bazen hatalı değerlendirmelere de neden olabileceğini görülmektedir.

Anahtar Kelimeler: CPT, zemin sinıfi, USCS, zemin kıvamı

\begin{abstract}
In all geotechnical studies the classification of soil is important both for correct foundation design and prediction of soil behavior. In practice, determination of the soil class can be carried out by drilling or research pit works in the field. Besides, approaches to determine of soil classes from Cone Penetration Test (CPT) data are used. This study was carried out to correlate the predicted USCS soil groups by CPT tests with actual test results which were carried out on the samples taken from field. For this purpose, 15 exploration drillings and 15 CPT test data which were carried out on an alluvial soil were
\end{abstract}


DEÜ FMD 23(67), 43-53, 2021

used. The results obtained by the experimental data on the samples taken from the research drillings were compared with the soil classes by CPT tests and correlated together. The findings revealed that the experimentally determined soil classes are considerably different from the soil classes determined by CPT end resistance values. The CPT method, which is insufficient to determine the plasticity of the soil, caused the SM group to be defined as "Sand - Clay". Same situation was evaluated for SC group it was observed that CPT data were defined this group as "Clay". This clearly demonstrates that soil classes that cannot be identified by in-situ sampling can lead to erroneous evaluations.

Keywords: CPT, Soil class, USCS, soil consistency

\section{Giriş}

Koni penetrasyon deneyi (CPT) zemin araștırmalarında sıklıkla kullanılan bir arazi deneyidir. Uygulamada, zemin profilinin bütünü boyunca veri alınmasını sağlaması açısından özellikle tercih edilebilmektedir. Bu olumlu özellikleri yanında pahalı olması, özel ekipman gerektirmesi ve zeminden örnek alınabilmesinin mümkün olmaması gibi çeșitli olumsuz özelliklere de sahip bir deney yöntemidir.

CPT deneyleri ile elde edilen veriler genel olarak uç sürtünme direnci $\left(\mathrm{q}_{\mathrm{c}}\right)$, çevre sürtünme değeri $\left(\mathrm{f}_{\mathrm{s}}\right)$ ve sürtünme oranı ( $\left.\mathrm{R}_{\mathrm{f}}\right)$ olarak doğrudan tanımlanmaktadır. Örnek alımının mümkün olmaması nedeniyle CPT verilerinden yola çıkılarak zemin türünün belirlenebilmesi sürekli bir araștırma konusu olmuştur. Bu konuda yapılmış zemin sınıflandırma yaklaşımlarının fazla oluşu, doğrudan ve hatasız olarak zemini sınıflandırabilmenin zorluğunu da ortaya koymaktadir.

Bu çalışma CPT deney verilerinden yola çıkılarak öngörülen zemin sinıflarının laboratuvar deneyleriyle belirlenen zemin sinıflandırma verileri ile uyumunu ortaya koymak amaciyla gerçekleştirilmiştir.

\section{2. Çalışma Yöntemi ve İnceleme Alanı}

Çalışma kapsamında Manisa İli - Alaşehir İlçesi sınırları içinde gerçekleştirilmiş bir elektrik üretim tesisi sanayi yapısı zemin araştırma çalışmalarında yapılan CPT arazi verileri kullanılmıştır. Arazi çalışmaların bütünü çalışma ekibi tarafından gerçekleștirilmiş ve ayrıca sahada her CPT lokasyonu için yapılan SPT deney verileri ile elde edilen örnekler ayrı ayrı değerlendirilmiştir. Zemin sınıflarının deneysel olarak belirlenmesi amaciyla temin edilen örnekler arazide yapılan sondajlardan elde edilmiştir.
Calıșma kapsamında Alașehir ovası alüvyal zemin çökelleri içerisinde açllan 15 adet CPT ve SPT araştırma kuyusuna ait veriler kullanılmıştır. CPT uygulamalarında Geomil GME500 marka deney ekipmanı ile klasik tipte CPT probları iki temel parametre olan uç mukavemeti qc ve çeper sürtünmesi fs değerlerini ölçmek amacıyla kullanılmıştır. Farklı derinliklerden örneklemelerin yapılabilmesi için açılan araştırma sondajlarında ise TSM 750 modelinde sondaj makinası kullanılmıştır. Sondajlar sadece zemin içerisinden örselenmiş örnek alımının sağlanabilmesi amacıyla açılmıştır (Şekil 1).
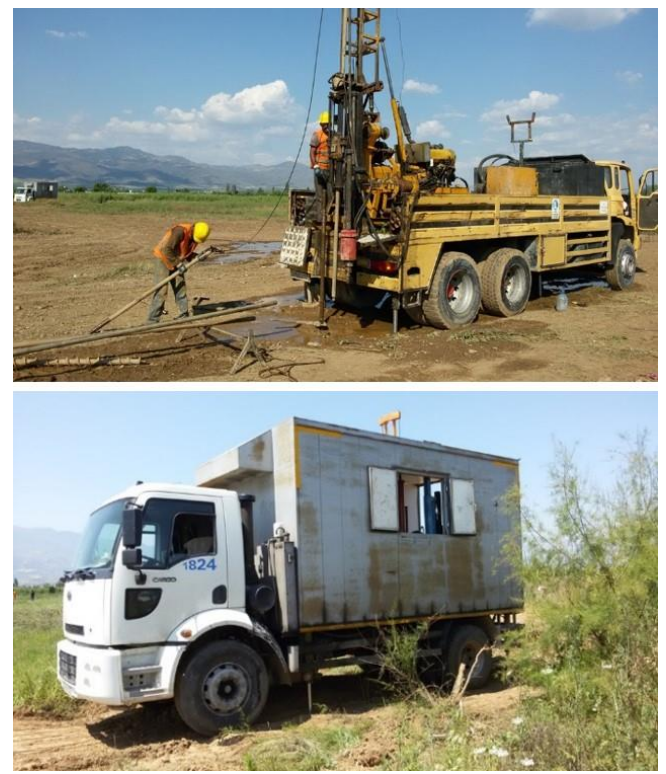

Şekil 1. İnceleme alanında gerçekleştirilen sondaj (üstte) ve CPT (altta) uygulamalarından görünümler

Elde edilen zemin örneklerinin CPT lokasyonlarını doğru bir şekilde temsil edebilmesi amacıyla sondaj delgilerinin CPT 
DEÜ FMD 23(67), 43-53, 2021

noktalarına mümkün olduğu kadar yakın olması sağlanmıștır (Şekil 2).

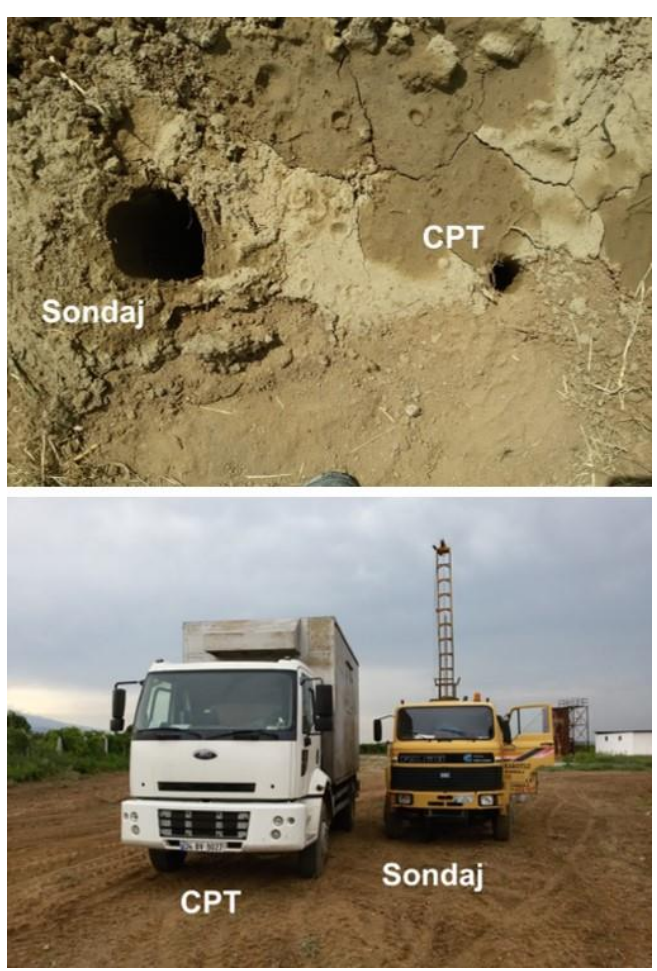

Şekil 2. Yapılan sondaj ve CPT uygulama noktalarının yakınlığı örneklerinin temsil ediciliğinin artırılmasını sağlamıștır

Yapılan sondaj çalıșmaları sırasında her $1.5 \mathrm{~m}$ derinlikte yapılan SPT deneyleri ile örselenmiș örnekler alınmıș ve ayrıca her kuyuda 2 adet olmak üzere farklı seviyelerden UD ile örselenmemiş örnekler alınmıştır. Sondaj çalıșmaları ile elde edilen örneklemelerden yola çıkılarak tanımlanmış kuyu logları ilk 5 sondaj kuyusu için olacak şekilde Şekil 3'de gösterilmiştir. Görüldüğü üzere alüvyal istif içerisinde küçük litolojik değişimlerin CPT deneylerindeki detayla elde edilmesi mümkün olmamaktadır. Buna karşılık CPT uygulaması doğrudan zemini tanımlamamakla birlikte $\mathrm{cm}$ ölçeğinde derinlik farkları için koni uç direnci $\left(\mathrm{q}_{\mathrm{c}}\right)$ ve çevre sürtünme $\left(\mathrm{f}_{\mathrm{s}}\right)$ değerlerinin değişimlerini sunmaktadır (Şekil 4).

$\mathrm{Bu}$ çalıșma kapsamında sondaj ile elde edilen örnekler (Sekil 5) laboratuvarda zemin sınıfını belirlemek amacıyla deneye tabi tutulmuşlardır.
Örnekleme yapılan derinlikler için CPT uygulamasına ait uç direnci $\left(\mathrm{q}_{\mathrm{c}}\right)$, çevre sürtünme $\left(\mathrm{f}_{\mathrm{s}}\right)$ ve sürtünme oranı $\left(\mathrm{R}_{\mathrm{f}}\right)$ değerleri belirlenmiş ve CPT'ye dayalı zemin siniflamaları Schmertmann [1], Douglas ve Olsen [2], Robertson vd. [3], Eslami ve Fellenius [4] yöntemleri esas alınarak gerçekleştirilmiştir.

\section{CPT Bazlı Zemin Sınıflama Sistemlerine Ait Literatür İncelemesi}

Koni penetrasyon test verilerinden yola çıkarak zemin sınıflamasına yönelik olarak yapılmış çok sayıda ve çeșitli çalışmalar mevcuttur. En eski çalışmalardan biri Begeman [5] tarafından yapılmış olup bu çalıșma ile sürtünme oranı (\%) değerine bağlı olarak zeminlerin 6 farklı grup içerisinde tanımlanmasını sağlayacak bir abak geliştirilmiştir.

Sanglerat vd. [6], $80 \mathrm{~mm}$ çaplı CPT deney aleti ile yaptığı araştırmalara dayanarak sürtünme oranı (\%) ve koni uç direnci (MPa) değerlerine bağlı olarak zeminleri kum, silt ve kil olarak tanımlanabilecek bir nomogram geliştirmişlerdir.

Schmertmann [1] tarafindan yapılan çalışma ile yazar, sürtünme oranı (\%) ve koni uç direnci (MPa) değerlerine bağlı olarak iri taneli zeminlerin gevşek ve sıkı, ince taneli zeminlerin ise kıvam durumlarını tanımlayan bir diğer zemin sınıflandırma abağı geliştirmiştir.

Searle [7], önermiș olduğu zemin sınıflandırma abağı ile CPT verilerinden yola çlkarak zeminlerin rölatif sıkılık, drenajsız kayma direnci ve içsel sürtünme açısı gibi parametreleri de tanımlamaya çalışmıştır.

Bu konudaki detaylı çalıșmalardan birisi Douglas ve Olsen [2] tarafından yapılmış olup kumlu zeminlerin yüksek koni direnci ve düșük sürtünme oranları, killi zeminlerin yüksek sürtünme oranları, organik zeminlerin düşük koni direnci ve yüksek sürtünme oranları, hassas zeminlerin ise düşük koni direnci ve düşük sürtünme oranları ile temsil edildiğini söylemişlerdir.

Vos [8], Begeman [5] tarafından önerilmiș olan sınıflandırmaya benzer bir bașka sınıflandırma yaparak CPT sürtünme oranlarına bağlı olarak bir başka sınıflandırma tablosunu önermiştir. 
DEÜ FMD 23(67), 43-53, 2021

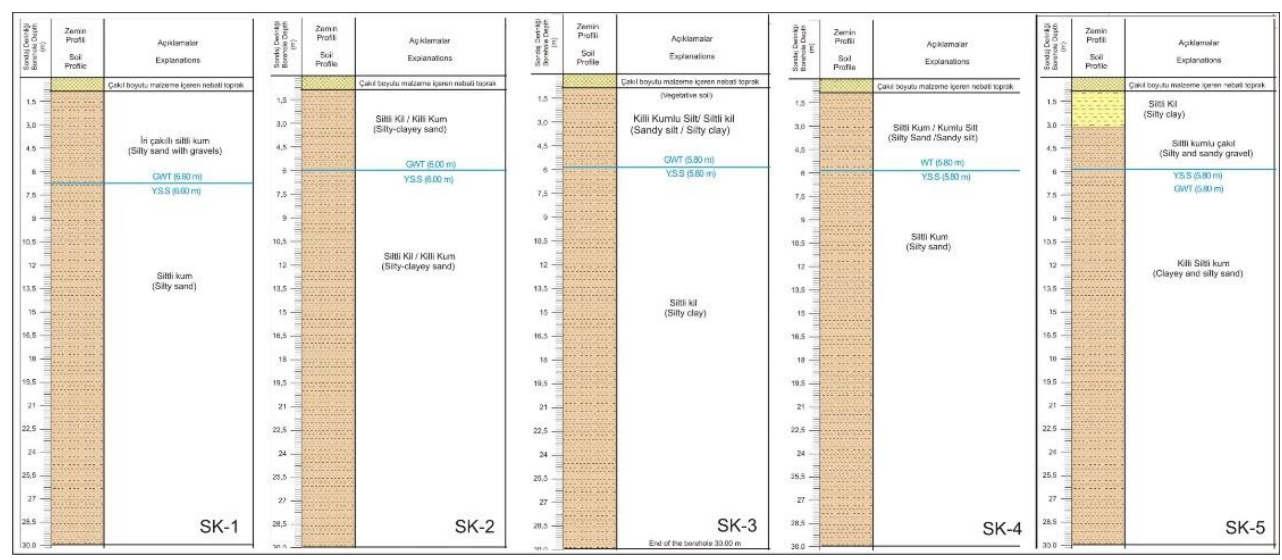

Şekil 3. İnceleme alanında yapılan sondaj çalışmaları ile elde edilmiş ve idealize edilmiş kuyu loglarına ait zemin profili

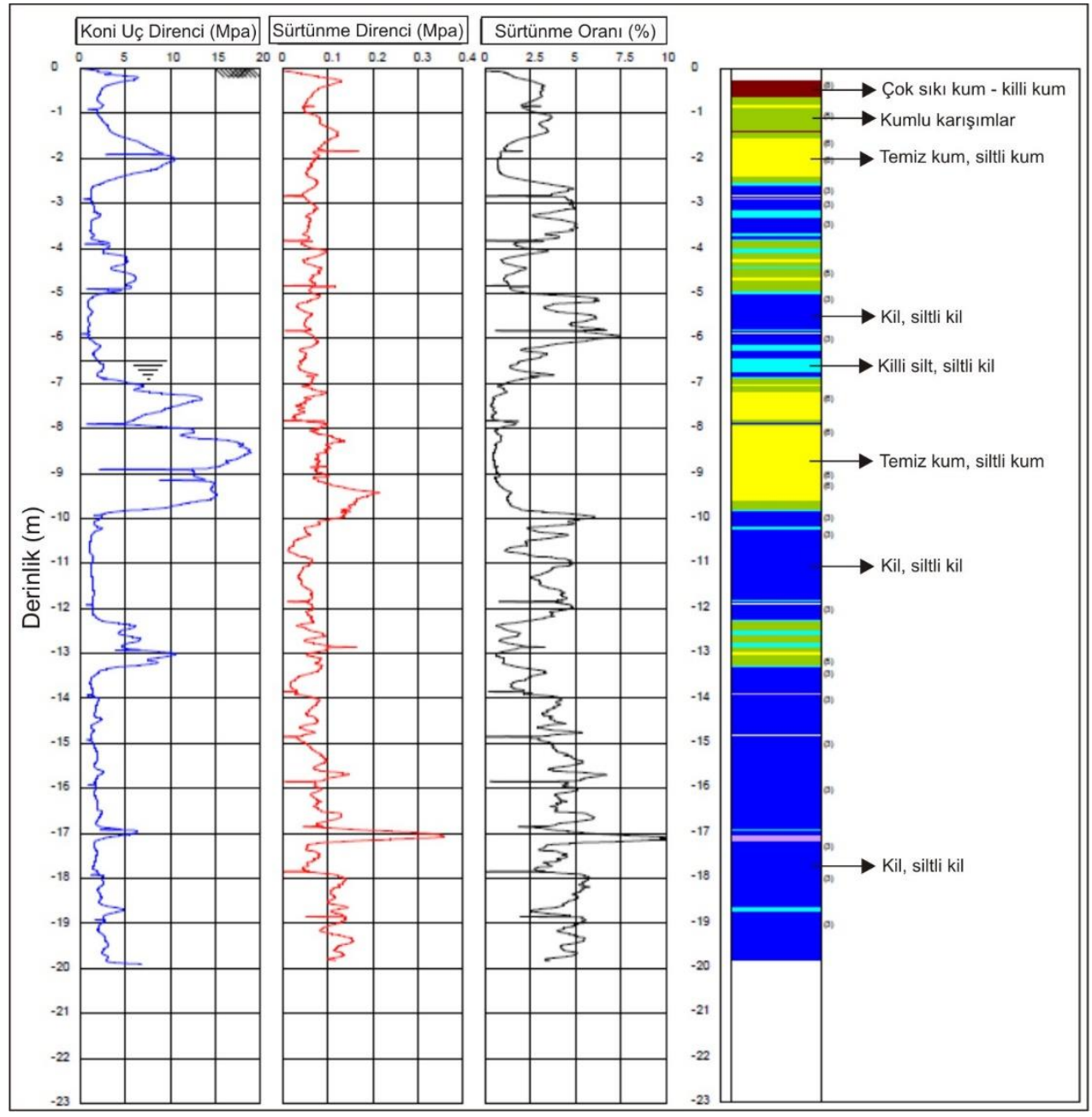

Şekil 4. CPT-1 ölçüm lokasyonu örneğinde elde edilmiş deney verileri ve olası zemin profili 
DEÜ FMD 23(67), 43-53, 2021
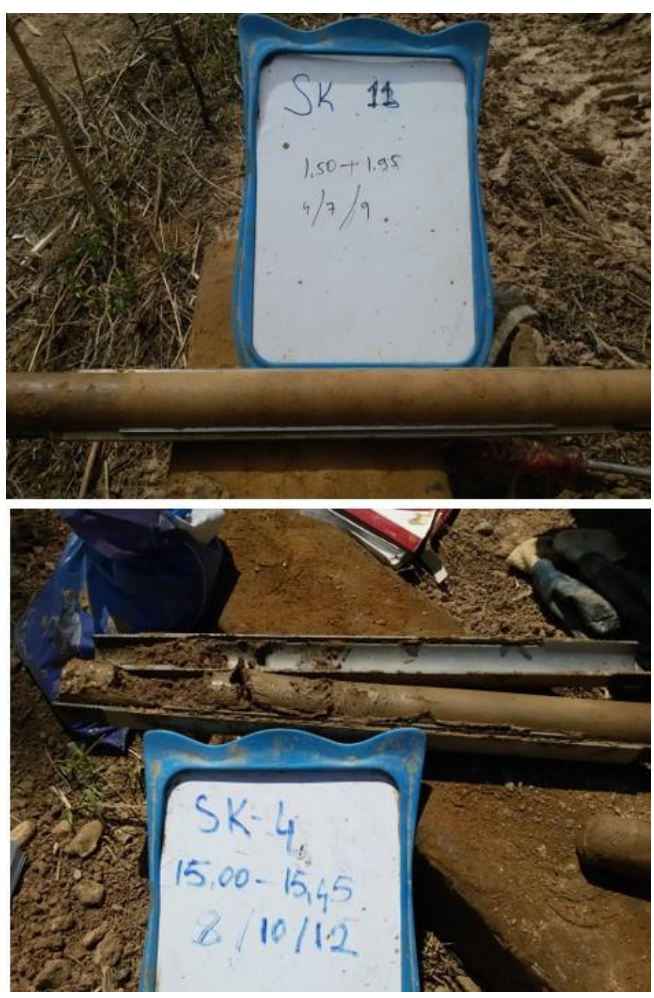

Şekil 5. Sondaj çalışmaları ile elde edilmiş zemin örneklerinin görünümleri

Jones ve Rust [9], tarafından geliștirilen zemin sınıflandırma çalışmasında ise CPT deneyleri sırasında ölçülen aşırı boşluk suyu basıncı değerleri kullanılmıştır. Bu sınıflandırmada, zemin üzerinde etkiyen toplan örtü yükü de dikkate alınmış olup bu açıdan da diğer sınıflandırma sistemlerinden de oldukça farklı bir değerlendirmeye sahiptir.

Robertson vd. [3] yapılan çalışmalardaki hatalı sonuçları da dikkate alarak zemin sınıflamasının $\left(q_{c}, u\right.$ ve $\left.f_{s}\right)$ parametre seti ile daha gerçekçi bir șekilde yapılabileceğini vurgulayarak bir sınıflama abağı önermișlerdir. Bu abakta zemin sinıflaması ( $q_{\mathrm{t}}$ ve $R_{f}$ ) parametreleri kullanılarak yapılmış ve zeminler; 1 . Hassas ince taneli zeminler, 2. Organik zeminler, 3. Kil, 4. Siltli kil kil, 5. Killi silt - siltli kil, 6. Kumlu silt - killi silt, 7. Siltli kum - kumlu silt, 8. Kum - siltli kum, 9. Kum, 10. Kum - çakıllı kum, 11. Çok katı ince taneli zeminler, 12. Așırı konsolide veya çimentolu kum - killi kum olmak üzere 12 farklı türde olmak üzere sınıflandırılmışlardır.
Senneset vd. [10], önermiş olduğu zemin sınıflandırma abağında, pozitif ve negatif boşluk suyu basınçlarına karşı CPT ile elde edilen koni uç direnci değerlerini kullanmıștır. Bu sınıflama sisteminin bir sınırlaması bulunmakta olup, uç direncinin $16 \mathrm{MPa}$ dan daha düşük olduğu zemin koşullarını temsil etmektedir.

Robertson [11], konik penetrasyon direncinin aynı özelliklere sahip zeminlerde SPT dirençlerinde olduğu gibi derinlikle arttığı gerçeğinden hareketle, örtü yüküne göre bir düzeltme yapılması gerektiğini vurgulamıştır. Bu amaçla daha önce kendi önermiş olduğu sinıflama sistemini kısmen revize ederek yeni bir sınıflama abağı haline getirmiştir.

Lunne vd. [12], literatürde yapılan yorumlardan CPT'de $q c$ ve $u$ ölçümlerinin sağlıklı olduğu, $f s$ ölçümlerinin ise sıklıkla hatalı değerler verdiği sonucunu önemle vurgulamıștır.

Eslami ve Fellenius [4], tarafından yapılan çalışmada CPTu verileri kullanılarak bir sınıflandırma abağı ortaya konulmuştur. Bu sınıflandırma abağında toplam ve efektif gerilmelerin belirlenmesine gerek duyulmamaktadır. Yazarlar bu çalışmalarında ayrıca CPT verilerini 102 farklı lokasyondan derledikleri veriler ıșığında kazık taşıma kapasitesinin belirlenmesinde de kullanmışlardır.

Eslami ve Fellenius [13], daha önce 1997 yılında yaparak literatüre kazandırdıkları çalışmaya ait verileri deneștirmeli olarak bir araya getirmiș ve CPT ve CPTu deney verilerinin zemin sinıflama etkinliklerini ele alarak değerlendirmişlerdir.

Baziar vd. [14] tarafindan yapılan çalıșmada CPT tabanlı zemin sınıflandırmasında kullanılan iki yöntem olan Robertson [11] ve Marr [15] sınıflandırmaları ele alınarak incelenmiştir. Toplam 15 veri noktası için elde edilen değerlendirmelere göre yazarlar Robertson [11] sınıflandırmasının iri taneli zeminler için ve Marr [15] sınıflamasının ise ince taneli zeminler için daha tutarlı ve doğru sonuçlar verdiğini ifade etmişlerdir.

$\mathrm{Bu}$ çalışmaların haricinde daha birçok çalışma CPT temelli verilerle zemin sınıfl, plastisitesi, organik madde içeriği, ince tane oranı değerlerini belirlemeyi amaçlamıștır. Yapılan çalışmaların fazla oluşu aslında bu konunun göründüğünden daha karmaşılk olduğunu ortaya koymaktadır. Özellikle CPT verilerinin normalize 
edilerek kullanılmaları durumunda, yani örtü gerilmelerinin bulunabilmesi için zemine ait örselenmemiş numunelere ihtiyaç duyulmaktadır. Bunun sağlanması koşulunda ise CPT'ye dayalı zemin sınıflandırma çalışmalarının ne amaçla yapılacağı sorgulanır hale gelmektedir. Zira örnek temini olması koşulunda laboratuvarda yapılacak deneysel çalışmalarla zemine ait bütün tane boyu parametrelerinin doğru bir şekilde belirlenmesi mümkün olmaktadır. $\mathrm{Bu}$ yüzden bu çalışma, güvenilir olduğu bilinen ve deneysel çalışmaları gerçekleștirilen alüvyal zemindeki verilerden yola çıkarak yeni bir sınıflama ortaya koymayı amaçlamamaktadır.

Bu çalıșma ile konunun karmașıklığının ortaya konulması ve aslında sınıflama için yapılması gerekenlerin ne kadar fazla hata payına yol açabileceğini göstermek olacaktır.

\section{USCS Sinıflandırması ve CPT Verileriyle Zemin Türlerinin Belirlenmesi}

CPT temelli zemin sınıflandırma çalışmalarında koni uç direnci $(\mathrm{MPa})$, çevre sürtünmesi $(\mathrm{MPa}$, $\mathrm{kPa}$ ) ve sürtünme oranı (\%) değerlerinden yola çıkılarak bahsedilen zemin sinıflandırma yöntemleri kullanılarak zemin türleri belirlenmiștir. Tablo 1, elde edilen 25 farklı örneklemeye ait sondaj kuyu numaralarını, derinliklerini, CPT verilerini ve laboratuvarda yapılan deneylerle belirlenmiş USCS zemin sınıflarını göstermektedir.

Tablo 1. Elde edilen örneklere ait lokasyon bilgileri ile CPT verileri ve laboratuvar deneyleri ile belirlenmiș USCS zemin sınıfları.

\begin{tabular}{ccccccc}
\hline Veri No & Sondaj No & Derinlik $(\mathrm{m})$ & $\mathrm{q}_{\mathrm{c}}(\mathrm{MPa})$ & $\mathrm{f}_{\mathrm{s}}(\mathrm{MPa})$ & $\mathrm{R}_{\mathrm{f}}(\%)$ & $\mathrm{USCS}$ \\
\hline 1 & SK-1 & 1,5 & 6,6834 & 0,0616 & 0,8503 & SM \\
2 & SK-1 & 6,5 & 4,672 & 0,0283 & 0,5802 & SM \\
3 & SK-2 & 16,5 & 3,0288 & 0,2206 & 7,2407 & CL \\
4 & SK-3 & 4,5 & 2,5882 & 0,0596 & 2,539 & CL \\
5 & SK-3 & 7,5 & 10,045 & 0,0436 & 0,4826 & SM \\
6 & SK-4 & 3 & 2,071 & 0,1019 & 4,6386 & SM \\
7 & SK-5 & 1,5 & 9,4321 & 0,1862 & 1,9747 & ML \\
8 & SK-5 & 13,5 & 1,2156 & 0,0205 & 1,6923 & SC \\
9 & SK-5 & 18 & 4,6755 & 0,241 & 5,3122 & CL \\
10 & SK-6 & 4,5 & 14,417 & 0,1226 & 0,9268 & CL \\
11 & SK-7 & 7,5 & 11,004 & 0,0446 & 0,4271 & SM \\
12 & SK-8 & 1,5 & 5,502 & 0,1031 & 1,8359 & ML \\
13 & SK-9 & 1,5 & 7,619 & 0,2171 & 2,8528 & ML \\
14 & SK-9 & 10,5 & 0,8166 & 0,0349 & 3,9076 & SC \\
15 & SK-10 & 3 & 1,6716 & 0,087 & 4,6341 & SM \\
16 & SK-11 & 4,5 & 2,381 & 0,0538 & 2,566 & SM \\
17 & SK-11 & 10,5 & 2,4175 & 0,0698 & 2,1082 & CL-ML \\
18 & SK-12 & 16,5 & 2,2965 & 0,1286 & 5,4758 & SC \\
19 & SK-13 & 12 & 2,023 & 0,152 & 6,184 & CL \\
20 & SK-13 & 16,5 & 3,5473 & 0,1975 & 5,8502 & SC \\
21 & SK-14 & 3 & 7,4251 & 0,2425 & 3,125 & CL \\
22 & SK-14 & 6 & 3,4916 & 0,0524 & 1,4751 & SM-SC \\
23 & SK-15 & 7,5 & 10,712 & 0,0321 & 0,301 & SC \\
24 & SK-15 & 9 & 12,711 & 0,0859 & 0,6805 & SM \\
25 & SK-15 & 12 & 1,4228 & 0,0666 & 4,6615 & SM \\
\hline & & & & &
\end{tabular}




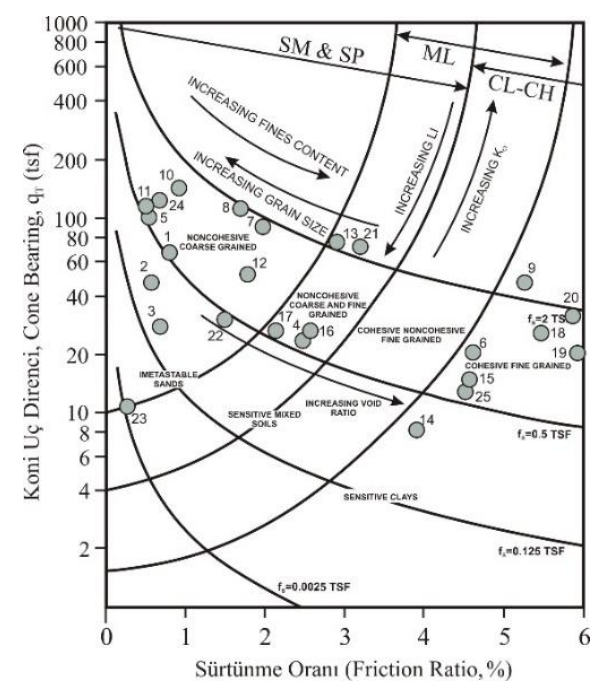

Şekil 6. İncelenen örneklerin Douglas ve Olsen [2] sınıflamasına göre tanımlanmış yerleri

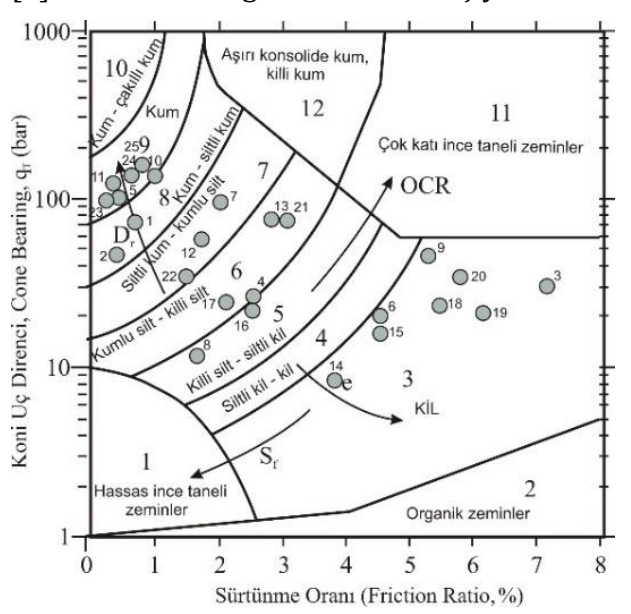

Şekil 7. İncelenen örneklerin Robertson vd. [3] sınıflamasına göre tanımlanmış konumları

Robertson ve Campanella [16] sinıflamasında koni uç direnci (MPa) ve sürtünme oranı (\%) değerleri kullanılmaktadır. Grafiğin yatay ekseni aritmetik, düşey ekseni ise logaritmik olarak teşkil edilmiştir. Yatay eksende yer alan sürtünme oranı değerleri en yüksek değer olan 6'da bitmektedir. Dolayısı ise bu değerden büyük sürtünme oranları için maksimum değer olan 6 alınmaktadır. Zemin sınıflaması içerisinde 5 grup yer almakta olup bu gruplar doğrudan tane boyu dağılımlarını içerecek şekilde olușturulmuștur. Bu çalıșma ile elde edilen CPT test verilerinin sınıflama abağındaki dağılımları Şekil 9'da görülmektedir.

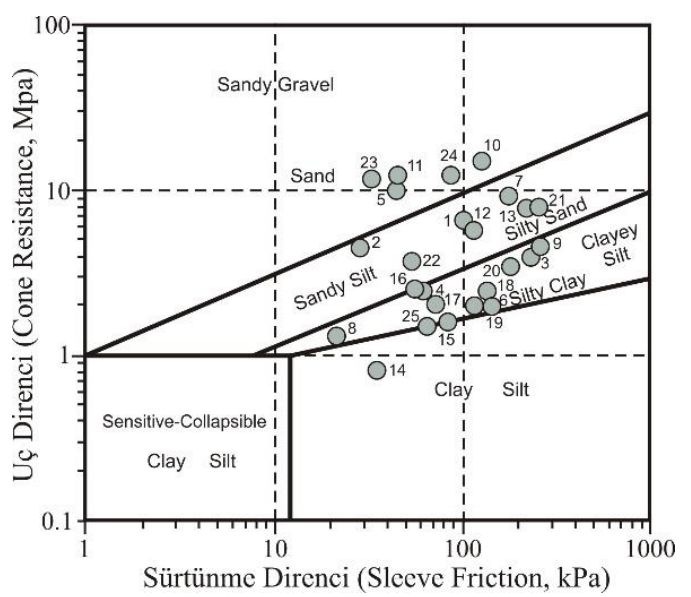

Şekil 8. İncelenen örneklerin Eslami ve Fellenius [4] sınıflamasına göre tanımlanmış konumları

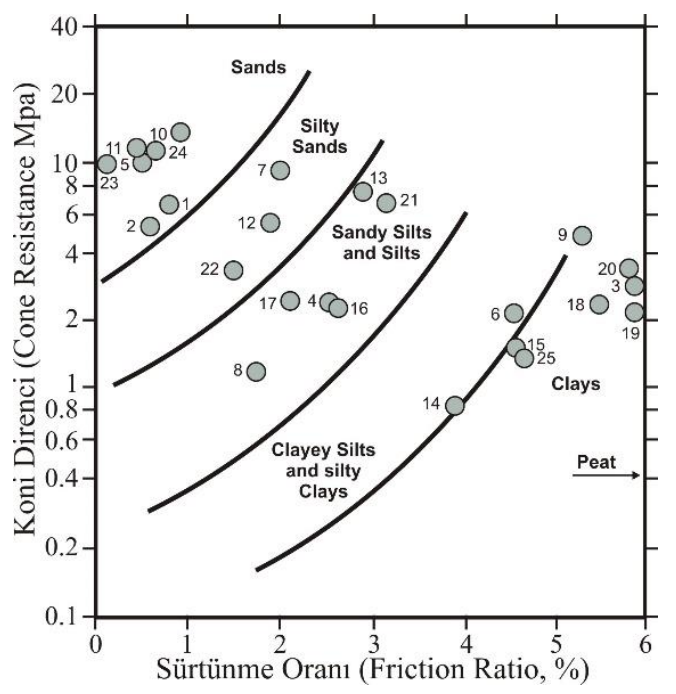

Şekil 8. İncelenen örneklerin Robertson ve Campanella [16] sınıflama abağı içerisindeki dağılımları

Bu çalıșma ile elde edilen CPT verilerinin bütünü laboratuvar deneyleri ile belirlenmiş olan zemin sınıfı değerleri (USCS) ile korele edilmişlerdir. $\mathrm{Bu}$ korelasyonların yapılabilmesi için CPT bazlı zemin sinıflama abağındaki zemin türleri de USCS sinıflaması türünden grup sembolleriyle ifade edilmişlerdir. Laboratuvar deneylerinin doğruluklarının bu tür çalışmalara ait yorumlamalarda önemli olması nedeniyle bu çalışma için elde edilen örnekler 2 ayrı laboratuvarda birbirlerini doğrulayacak şekilde deneye tabi tutulmuşlardır. Zeminlerin bütünü için ıslak eleme usulü elek analizleri 
gerçekleştirilmiş ve her deney numunesi için kıvam parametreleri de belirlenmiştir.

Yapılan CPT deneyleri ile belirlenmiş olan zemin sinıflarl, deney yapılan test seviyelerinden sondajlarla alınan zemin numuneleri ile kıyaslandığında aşağıdaki sonuçların elde edildiği görülmektedir.

1-İncelenen 4 farklı sınıflama yöntemi için zemin sınıfları arasında farklılıklar bulunmaktadır.
2-CPT temelli zemin sinıflamalarında kum ve kil ayırımlarının çoğu kez yapılabildiği ancak iri tane içerisine ince tanenin girmesi durumunda zemin sinıflarında yine farklılıklar bulunmaktadır.

3-Bu çalışma kapsamında incelenen 25 farklı seviyeye ait örnekler için elde edilmiş CPT bazlı sinıflamalardan Robertson vd. [3] yöntemi 16 örnekleme ile en doğru tanımlama yöntemi olarak görülmüștür.

Tablo 2. CPT bazlı zemin sınıflamaları ile elde edilen zemin gruplarının laboratuvar deneyleri ile bulunan USCS zemin sınıfları ile birlikte tanımlanmaları. (Gri zonlu yazılar bir birleriyle uyumlu tanımlamaları gösterir)

\begin{tabular}{|c|c|c|c|c|c|}
\hline $\begin{array}{c}\text { Örnek } \\
\text { No }\end{array}$ & $\begin{array}{l}\text { USCS } \\
\text { Sinıfi } \\
\end{array}$ & $\begin{array}{c}\text { Douglas ve } \\
\text { Olsen [2] }\end{array}$ & $\begin{array}{c}\text { Robertson vd. } \\
{[3]}\end{array}$ & $\begin{array}{c}\text { Eslami ve } \\
\text { Fellenius [4] }\end{array}$ & $\begin{array}{c}\text { Robertson ve } \\
\text { Campanella [16] }\end{array}$ \\
\hline 1 & SM & SM/ SP & \multirow{3}{*}{$\begin{array}{l}\text { SM } \\
\text { SM } \\
\text { CL }\end{array}$} & $\mathrm{SM} / \mathrm{ML}$ & SM/SC/SW/SP \\
\hline 2 & SM & $\mathrm{SM} / \mathrm{SP}$ & & $\mathrm{SM} / \mathrm{ML}$ & SM/SC/SW/SP \\
\hline 3 & CL & $\mathrm{SM} / \mathrm{SP}$ & & ML / MH & $\mathrm{CL} / \mathrm{CH}$ \\
\hline 4 & CL & $\mathrm{SM} / \mathrm{SP} / \mathrm{ML}$ & \multirow{2}{*}{$\begin{array}{c}\text { ML } \\
\text { SW / SP }\end{array}$} & CL & ML \\
\hline 5 & SM & $\mathrm{SM} / \mathrm{SP}$ & & SM & SM/SC/SW/SP \\
\hline 6 & SM & $\mathrm{CL} / \mathrm{CH}$ & $\mathrm{CL} / \mathrm{CH}$ & ML / MH & \multirow{2}{*}{$\begin{array}{c}\mathrm{ML} / \mathrm{CL} \\
\mathrm{SM}\end{array}$} \\
\hline 7 & ML & $\mathrm{SM} / \mathrm{SP}$ & \multirow{3}{*}{$\begin{array}{c}\mathrm{SM} / \mathrm{ML} \\
\mathrm{SC} \\
\mathrm{CL} / \mathrm{CH}\end{array}$} & SM / ML & \\
\hline 8 & SC & $\mathrm{SM} / \mathrm{SP}$ & & CL-ML & ML \\
\hline 9 & CL & $\mathrm{CL} / \mathrm{CH}$ & & ML / MH & $\mathrm{CL} / \mathrm{CH}$ \\
\hline 10 & CL & SM/ SP & SW / SP & $\mathrm{SM} / \mathrm{SC}$ & $\mathrm{SM} / \mathrm{SC} / \mathrm{SW} / \mathrm{SP}$ \\
\hline 11 & SM & $\mathrm{SM} / \mathrm{SP}$ & \multirow{2}{*}{$\begin{array}{c}\text { SW / SP } \\
\text { SM-SC / ML }\end{array}$} & \multirow{2}{*}{$\begin{array}{l}\mathrm{SM} / \mathrm{SC} \\
\mathrm{SM} / \mathrm{ML}\end{array}$} & $\mathrm{SM} / \mathrm{SC} / \mathrm{SW} / \mathrm{SP}$ \\
\hline 12 & ML & $\mathrm{SM} / \mathrm{SP}$ & & & SM \\
\hline 13 & ML & SM/ SP/ML & ML & $\mathrm{SM} / \mathrm{ML}$ & ML \\
\hline 14 & $\mathrm{SC}$ & $\mathrm{CL} / \mathrm{CH}$ & $\mathrm{CL} / \mathrm{CH}$ & $\mathrm{CL} / \mathrm{CH}$ & ML/CL \\
\hline 15 & SM & $\mathrm{CL} / \mathrm{CH}$ & $\mathrm{CL} / \mathrm{CH}$ & $\mathrm{CL} / \mathrm{CH}$ & $\mathrm{CL} / \mathrm{CH}$ \\
\hline 16 & SM & SM/ SP/ML & \multirow{2}{*}{$\begin{array}{l}\mathrm{SM} / \mathrm{ML} \\
\mathrm{CL}-\mathrm{ML}\end{array}$} & \multirow{2}{*}{$\begin{array}{c}\text { SM / ML } \\
\text { CL-ML }\end{array}$} & ML \\
\hline 17 & CL-ML & $\mathrm{SM} / \mathrm{SP} / \mathrm{ML}$ & & & ML \\
\hline 18 & $\mathrm{SC}$ & $\mathrm{CL} / \mathrm{CH}$ & $\mathrm{CL} / \mathrm{CH}$ & \multirow{2}{*}{$\begin{array}{l}\text { ML / MH } \\
\text { ML / MH }\end{array}$} & $\mathrm{CL} / \mathrm{CH}$ \\
\hline 19 & CL & $\mathrm{CL} / \mathrm{CH}$ & $\mathrm{CL} / \mathrm{CH}$ & & $\mathrm{CL} / \mathrm{CH}$ \\
\hline 20 & SC & $\mathrm{CL} / \mathrm{CH}$ & $\mathrm{CL} / \mathrm{CH}$ & ML / MH & $\mathrm{CL} / \mathrm{CH}$ \\
\hline 21 & $\mathrm{CL}$ & SM/ SP/ML & CL-ML & $\mathrm{SM} / \mathrm{ML}$ & ML \\
\hline 22 & SM-SC & $\mathrm{SM} / \mathrm{SP}$ & SM-SC / ML & $\mathrm{SM} / \mathrm{ML}$ & SM \\
\hline 23 & $\mathrm{SC}$ & $\mathrm{SM} / \mathrm{SP}$ & SW / SP & $\mathrm{SM} / \mathrm{SC}$ & SM/SC/SW/SP \\
\hline 24 & SM & $\mathrm{SM} / \mathrm{SP}$ & \multirow{2}{*}{$\begin{array}{l}\text { SW / SP } \\
\text { SW / SP }\end{array}$} & SM / SC & $\mathrm{SM} / \mathrm{SC} / \mathrm{SW} / \mathrm{SP}$ \\
\hline 25 & SM & $\mathrm{CL} / \mathrm{CH}$ & & CL-ML & $\mathrm{CL} / \mathrm{CH}$ \\
\hline \multicolumn{2}{|c|}{ Uygun Sinıf } & 9 & 16 & 12 & 10 \\
\hline \multicolumn{2}{|c|}{ \% Uyum } & 36 & 64 & 48 & 40 \\
\hline
\end{tabular}


DEÜ FMD 23(67), 43-53, 2021

4-Literatürde bilinen yöntemlerden biri olan Douglas ve Olsen [2] sinıflamasının büyük oranda iri - ince tane ayırımında hatalı sonuçlar verebildiği tespit edilmiştir.

5-İncelenen sinıflandırmalar bir arada değerlendirildiğinde aralarında büyük farklılıkların bulunduğu dikkati çekmektedir.

6-CPT bazlı sınıflamaların bütünü iri taneli zeminler için derecelenme ve ince taneli zeminler için kıvam durumunu yorumlayamamaktadırlar. Özellikle sıvılaşma analizleri için değerlendirilmesi önemli bir parametre olan iyi veya kötü derecelenme durumu sinıflama sistemleri tarafindan tanımlanamamaktadır.

7-İnceleme yapılan saha içerisinde CL-ML çift grup sembolü ile tanımlanan lokasyon için doğru zemin sinifları Robertson vd. [3] ile Eslami ve Fellenius [4] tarafından verilmiştir. Bununla birlikte özellikle Robertson vd. [3] sınıflamasının ince taneli zeminlerin (kil ve silt) genel tanımlaması için büyük ölçüde doğru sonuçlar verdiği belirlenmiștir.

\section{Yeraltı Suyunun CPT Verileri Üzerindeki Etkilerinin İncelenmesi}

İnceleme alanı içerisinde yeraltı suyu 5.80 ile $6.60 \mathrm{~m}$ seviyeleri arasında değişmektedir. Ortalama yeraltı suyu derinliği $6.00 \mathrm{~m}$ olarak belirlenmiștir. Bu bölümde yeraltı su seviyesinin CPT uç direnci ve çevre sürtünmesi değerleri üzerindeki etkileri ele alınmıs ancak bu etkilerin zemin sınıflama çalışmalarındaki etkilerinin ortaya konulması bu çalışmaya konu edilmemiştir. Bununla birlikte elde edilmiş sonuçlar ortalama değerleri ifade edecek şekilde değerlendirildiğinde, SM grubu zeminlerde yeraltı suyu seviyesi altında uç direnci değerlerinin yaklaşık \% 45 oranında düştügüu, CL türü zeminlerde ise yeraltı su seviyesi altında koni uç direnci ortalama değerlerinde yaklaşık $\%$ 42'lik bir artış meydana geldiği görülmektedir (Şekil 9).

Aynı zemin grupları için yeraltı suyu konumuna göre çevre sürtünme direnci değerleri de incelenmiştir. SM grubu zeminler için çevre sürtünme direnci ortalama değeri yeraltı su seviyesi altında yaklaşık \% 25 azalmıştır. CL grubu zeminler için bu ilișki sorgulandığında sürtünme direnci ortalama değerinin yeraltı su seviyesi altında yaklaşık \% 17 oranında arttığı görülmüştür (Şekil 10).
Elde edilen bu değerler, CPT verilerine dayalı zemin sınıflandırma çalıșmalarında ortamda yeraltı suyunun olması veya olmaması koşullarının etkili olacağını da açıkça ortaya koymaktadır. $\mathrm{Bu}$ durum, CPT verilerinin yeraltısuyu açısından da değerlendirilebilecek şekilde yorumlanmasını gerektirmektedir.

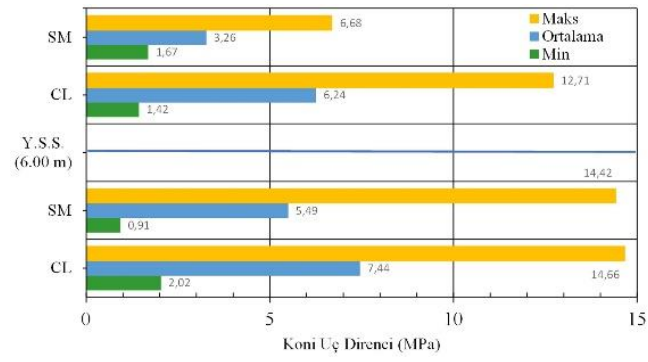

Şekil 9. Zemin türlerine bağlı olarak koni uç direnci değerlerinin yeraltı suyu konumuna göre değișimleri

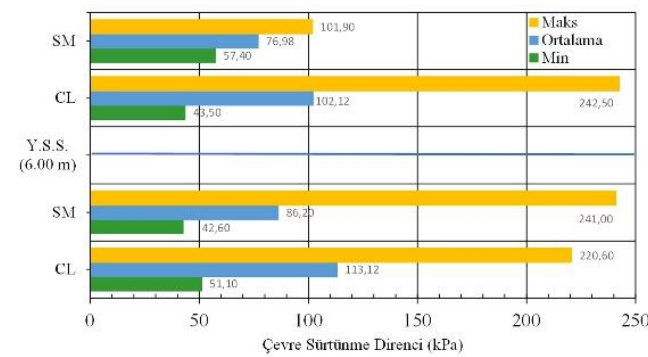

Şekil 10. Zemin türlerine bağlı olarak çevre sürtünme direnci değerlerinin yeraltı suyu konumuna göre değişimleri

\section{Sonuçlar}

CPT deney ekipmanını üreten Hollanda kökenli firmalar (Geomil, Gouda, Sds, APVandenberg vb.) deney verilerinden zemin sınıfını belirlemede yazılımları içerisinde Robertson [11] tarafından önerilmiş sınıflama abağını kullanmaktadırlar. Bu sınıflandırma için hem koni uç direncinin ve hem de sürtünme oranı değerlerinin efektif jeolojik gerilmeye göre normalize edilmeleri gerekmektedir. $\mathrm{Bu}$ amaçla zemin parametrelerinin deneysel olarak belirlenmeden yaklaşık sayısal değerler alınması zaten hassas ve karmașık olan sınıflama sistemlerinin belirli ölçülerde başarısız olmasına neden olabilmektedir.

Literatürde var olan ve bu çalıșmada bile ancak kısıtlı sayıda incelenmesi mümkün olan 
DEÜ FMD 23(67), 43-53, 2021

çalıșmaların çokluğu aslında CPT verilerine dayalı zemin sinıflama konusunun karmașıklığının bir ifadesi olarak değerlendirilebilir. Ortaya konulan sınıflama sistemlerinin çok olmasına karşın her birinin diğerleri ile örtüşmeyecek şekilde farklılıklar sunması da doğrudan test ve analiz yöntemlerinin önemini ortaya koymaktadır. $\mathrm{Bu}$ durumun bir yansıması olarak, doğrudan ve sadece CPT verileri ile yapılacak zemin sinıflama çalışmalarının örtüşme oranlarının üşük olmasına neden olabilecektir. Bu yüzden zemin sınıflaması ve ayrıca bütün mekanik test verilerinin doğrudan ve yerinde yaplacak örneklemelerle elde edilmesi önemli bir tercih olarak karşımıza çıkmaktadır.

Bu çalışma kapsamında 8 ayrı CPT temelli zemin sınıflama sistemi incelenmiş ve bunlardan 4 tanesi üzerinde uygulamaya dönük bir araștırma gerçekleştirilmiştir. 25 deney verisi üzerinde yapılan laboratuvar deney sonuçları CPT verileri ile sağlanan zemin sınıfları ile deneştirilmiştir. Laboratuvar deney sonuçlarının uyumluluklarının artırılması amacıyla çalışmada 2 ayrı laboratuvar (Pamukkale Üniversitesi Müh. Fak. Zemin ve Kaya Mekaniği Laboratuvarı ve SF Zemin ve Yapı Laboratuvarı) deney imkanlarından faydalanılmıştır.

$\mathrm{Bu}$ çalışma kapsamında incelenen 25 farklı seviyeye ait örnekler için elde edilmiş CPT bazlı sinıflamalardan Robertson vd. [3] yöntemi 16 örnekleme (\%64) ile en bașarılı tanımlama yöntemi olarak değerlendirilmiştir. Sınıflama yöntemlerinden biri diğeri olan Douglas ve Olsen [2] sınıflamasının büyük oranda iri - ince tane ayırımında hatalı sonuçlar verebildiği tespit edilmiștir.

CPT bazlı sınıflamaların bütünü iri taneli zeminler için derecelenme ve ince taneli zeminler için kıvam durumunu yorumlayamamaktadırlar. Özellikle sıvılaşma analizleri için değerlendirilmesi önemli bir parametre olan iyi veya kötü derecelenme durumu siniflama sistemleri tarafindan tanımlanamamaktadır.

İnceleme yapılan saha içerisinde CL-ML çift grup sembolü ile tanımlanan lokasyon için başarılı zemin sinıfı tahminleri Robertson vd. [3] ile Eslami ve Fellenius [4] tarafından önerilen sınıflamalardan alınabilmiștir. Bununla birlikte özellikle Robertson vd. [3] sınıflamasının ince taneli zeminlerin (kil ve silt) genel tanımlaması için önemli ölçüde gerçekçi sonuçlar verdiği belirlenmiştir.

İnceleme alanında yeraltı suyu seviyesi yaklașık $6.0 \mathrm{~m}$ derinlikte yer almaktadır. SM grubu zeminlerde yeraltı suyu seviyesi altında uç direnci değerlerinin yaklaşık \% 45 oranında düştügü görülmektedir. CL türü zeminlerde ise yeraltı su seviyesi altında koni uç direnci ortalama değerlerinde yaklaşık \% 42'lik bir artış meydana gelmektedir. Benzer durum sürtünme direnci değerleri için incelendiğinde SM grubu zeminler için çevre sürtünme direnci ortalama değeri yeraltı su seviyesi altında yaklaşık \% 25 azalmıştır. CL grubu zeminler için bu ilişki sorgulandığında sürtünme direnci ortalama değerinin yeraltı su seviyesi altında yaklașık \% 17 oranında arttığı görülmüştür. Bu durum, CPT'ye dayalı zemin sınıflama çalışmalarında yeraltı suyu etkisinin de dikkate alınması gerektiğini ortaya koymaktadır. Bu amaçla, deney ekipmanlarının boșluk suyu basıncı değerlerini de ölçecek şekilde teçhiz edilmiş olmasına önem verilmelidir.

Bütün diğer arazi deneylerinde olduğu gibi CPT verileri ile mühendislikte kullanılan ve belirlenmesi amaçlanan her parametrenin tahmin edilebilmesi mümkün değildir. Daha gerçekçi değerlendirmeler için mümkün olması halinde doğrudan örneklemelerin yapılabilidği çalışma yöntemleriyle elde edilen verilerin belirli ölçüde de olsa karşılaştırmalarının dikkate alınmasında yarar vardır.

\section{Teşekkür}

Bu çalışma, bir enerji üretim tesisi sanayi yapısı temel araştırmaları kapsamında yapılan arazi inceleme ve deneyleri ile gerçekleştirilmiştir. Arazi çalışmaları sırasında desteklerini esirgemeyen ve verilerin temininde yardımc olan "Geo Sound Mühendislik" firması yetkilisi Jeoloji Mühendisi Sn. Didem ÇOBANOĞLU'na teşekkürü bir borç biliriz. Araziden elde edilen numunelerin sinıflandırma deneylerinin yapımında Pamukkale Üniversitesi Müh. Fak. Zemin ve Kaya Mekaniği Laboratuvarı ve SF Zemin ve Yapı Laboratuvarından faydalanılmıștır. Çalışmalarındaki titizliklerinden dolayı her iki laboratuvar yetkililerine de ayrıca teșekkür ederiz.

\section{Kaynakça}

[1] Schmertmann, J.H. 1978. Guidelines for cone test, performance, and design, Federal Highway 
DEÜ FMD 23(67), 43-53, 2021

Administration, Report FHWA-TS-78209, Washington, 145

[2] Douglas, B.J., Olsen, R.S. 1981. Soil classification using electric cone penetrometer, American Society of Civil Engineers, ASCE, Proceedings of Conference on Cone Penetration Testing and Experience, (209-227). St. Louis, October $26-30$.

[3] Robertson, P.K., Campanella, R.G., Gillespie, D., Grieg, J. 1986. Use of piezometer cone data, Proceedings of American Society of Civil Engineers, ASCE, In-Situ 86 Specialty Conference, (1263-1280). Edited by S. Clemence, Blacksburg, June 23 - 25, Geotechnical Special Publication GSP No. 6.

[4] Eslami, A., Fellenius, B.H. 1997. Pile capacity by direct CPT and CPTu methods applied to 102 case histories, Canadian Geotechnical Journal, 34(6) 880-898.

[5] Begemann, H.K.S. 1965. The friction jacket cone as an aid in determining the soil profile, Proceedings of the 6th International Conference on Soil Mechanics and Foundation Engineering, ICSMFE, 2, (17 - 20). Montreal, September 8 - 15

[6] Sanglerat, G., Nhim, T.V., Sejourne, M., Andina, R. 1974. Direct soil classification by static penetrometer with special friction sleeve, Proceedings of the First European Symposium on Penetration Testing, ESOPT-1, 2.2, (337-344). June 5 - 7, Stockholm.

[7] Searle, I.W. 1979. The interpretation of Begemann friction jacket cone results to give soil types and design parameters, Proceedings of 7 th European Conference on Soil Mechanics and Foundation Engineering, ECSMFE, (2265-270). Brighton.

[8] Vos, J.D. 1982. The practical use of CPT in soil profiling, Proceedings of the Second European Symposium on Penetration Testing, ESOPT-2, 2, (933-939). Amsterdam, May 24-27.

[9] Jones, G.A., Rust, E. 1982. Piezometer penetration testing, CUPT, Proceedings of the 2nd European Symposium on Penetration Testing, ESOPT-2, 2, (607-614). Amsterdam, May 24 - 27.

[10] Senneset, K., Sandven, R., Janbu, N. 1989. Evaluation of soil parameters from piezocone test, In-situ Testing of Soil Properties for Transportation, Transportation Research Record, No. 1235 Washington, D. C., 24-37.

[11] Robertson, P.K. 1990. Soil classification using the cone penetration test, Canadian Geotechnical Journal, 27(1), 151-158.

[12] Lunne, T., Robertson, P.K., Powell, J.J.M. 1997. Cone penetration testing in geotechnical practice. Blackie Academic \& Professional, 312.

[13] Eslami, A., Fellenius, B.H. 2004. CPT And CPTU Data For Soil Profile Interpretation: Review of Methods and A Proposed New Approach, Iranian Journal of Science \& Technology, Transaction B, Vol. 28, No. B1, $69-86$.

[14] Baziar, M.H., Ashari, M.E., Zadeh, S. 2004. Comparison of Soil Classification Methods Using CPT Results, International Conference on Case Histories in Geotechnical Engineering, Paper No 3.06, pp. 1- 4 April 13-17, NewYork.

[15] Marr, L.S. 1981. Offshore applications of the cone penetrometer. Cone penetration testing and experience, St. Louis, MO, Proceedings, 456-476.
[16] Robertson, P.K., Campanella, R.G. 1983. Interpretation of cone penetrometer tests, Part I sand. Canadian Geotechnical Journal, 20(4), 718733. 